Document downloaded from:

http://hdl.handle.net/10251/104130

This paper must be cited as:

Payri, R.; Gimeno, J.; Marti-Aldaravi, P.; Alarcón-Herrera, MY. (2017). Numerical simulation of needle movement nozzle flow coupled with spray for a diesel injector using an Eulerian spray atomization model. Journal of the Brazilian Society of Mechanical Sciences and Engineering. 7(39):2585-2592. doi:10.1007/s40430-017-0801-1

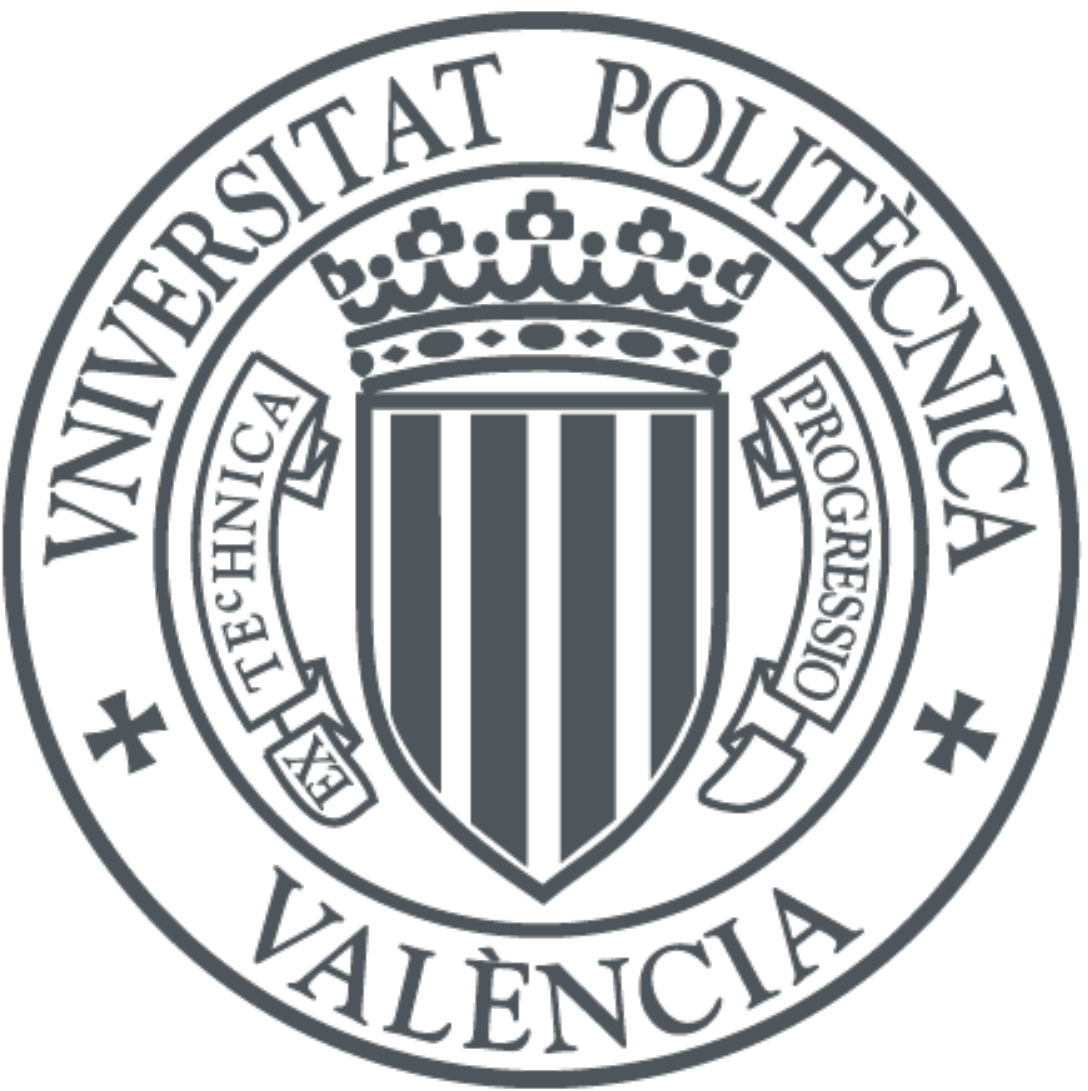

The final publication is available at

http://doi.org/10.1007/s40430-017-0801-1

Copyright Springer-Verlag

Additional Information 


\title{
Numerical Simulation of Needle Movement Nozzle Flow Coupled with Spray for a Diesel Injector Using an Eulerian Spray Atomization Model
}

\author{
Raúl Payri · Jaime Gimeno • Pedro \\ Martí-Aldaraví • Mary Alarcón
}

Received: date / Accepted: date

\begin{abstract}
The injector dynamics have a strong impact on spray behavior, therefore on combustion efficiency and pollutant emissions. Nozzle flow and spray coupled simulations are useful tools to analyze the effect of nozzle geometry, and they could be used also to study the effect of needle movement. In this work, three different approximations to the same needle lift law are employed in an Eulerian Spray Atomization (ESA) model. The main advantage of this model is that is able to simulate nozzle flow and spray seamlessly. Engine Combustion Network (ECN) Spray A conditions are simulated. Results show that the experimental needle lift law can be used without any fitting to a smoothed expression, but all details of the needle dynamics must be considered in order to properly predict mass flow rate and spray penetration. Additionally, it has been shown that needle dynamics has a strong impact on heating effects inside the nozzle.
\end{abstract}

Keywords Multi-phase · CFD · needle dynamics · atomization · fuel injection · moving mesh

\author{
R. Payri \\ CMT - Motores Térmicos, Universitat Politècnica de València \\ J. Gimeno \\ CMT - Motores Térmicos, Universitat Politècnica de València \\ P. Martí-Aldaraví \\ CMT - Motores Térmicos, Universitat Politècnica de València \\ Tel.: +34-963877650 \\ Fax: +34-963877659 \\ E-mail: pedmar15@mot.upv.es \\ M. Alarcón \\ CMT - Motores Térmicos, Universitat Politècnica de València
}


Final author version, cite as:

Payri, R., Gimeno, J., Mart-Aldarav, P. et al. "Numerical simulation of needle movement nozzle flow coupled with spray for a diesel injector using an Eulerian spray atomization model", J Braz. Soc. Mech. Sci. Eng., 39(7), pp. 2585-2592, (2017). doi:10.1007/s40430-017-0801-1

\section{Introduction}

Fuel injection conditions such as injection pressure and velocity, even injected fuel temperature [3], greatly affect spray development, and so combustion efficiency. Nonetheless, the study of flow characteristics inside Diesel nozzles is tricky due to their small characteristic length and hard testing conditions (very high pressure and velocity) [2]. It gets more complicated when dual fuel or multiple-injection strategies are used to improve combustion efficiency [?]. That is the reason why Computational Fluid Dynamics (CFD) is widely used to study such kind of flows $[4,5]$. These techniques model the real domain generally by finite volume discretization. Therefore, the geometry of the nozzle must be very well known in advance.

In order to obtain geometrical details of Diesel nozzle, silicone mold technique [6] has been widely used over the years. Nevertheless, new powerful techniques such as X-ray tomography [7] have been also successfully employed. In fact, this last technique not only allows obtaining the sizing of the nozzle with a resolution of microns, but also the time resolved position of the needle and measurements in the dense region of the spray [8]. It is known that needle movement affects spray behavior (and so combustion efficiency) specially during opening and closing transients $[9,10]$.

From another point of view, the in-nozzle flow pattern defines the spray behavior and characteristics [11]. Though nozzle flow and spray are clearly linked, few studies have been able to analyze both seamlessly. Experimentally, hydraulic behavior of the nozzle is obtained first, and then in completely different test rigs the spray is visualized and characterized. Computationally, it is common to simulate first the internal flow, and then use both experimental and computational data as boundary condition for spray simulations. In the process there are always losses of information due to the different length and time scales. Nonetheless, modelers in the last decade have made an effort to advance in that topic, as proved by the spreading of the use of Eulerian models for the sprays $[12,13]$.

Under this framework, the objective of this work is to employ an already existing Eulerian model, able to simulate nozzle flow and spray at the same time [14], to computationally address the effects of needle movement on the spray behavior. To do so, Spray A conditions of Engine Combustion Network (ECN) [16] are considered. Nozzle of Spray A is very well characterized in terms of geometry and flow characteristics, including needle lift measurements. However, the time resolution used for measuring needle velocity may not be high enough, then it is possible that some post-processing (i.e. moving average) of the experimental signal is required. 
Final author version, cite as:

Payri, R., Gimeno, J., Mart-Aldarav, P. et al. "Numerical simulation of needle movement nozzle flow coupled with spray for a diesel injector using an Eulerian spray atomization model", J Braz. Soc. Mech. Sci. Eng., 39(7), pp. 2585-2592, (2017). doi:10.1007/s40430-017-0801-1

\section{Methodology}

\subsection{Code description}

The Eulerian Spray Atomization (ESA) is a homogeneous model built to simulate non-evaporative conditions so far [14]. When compared with other approaches to simulate nozzle flow with moving needle and also the spray behavior (for example the work of Anvari et al. [15]), the main advantage of this model is that allows to simulate both domains seamlessly. This avoids the use of interpolation algorithms for coupling (one or two-ways). Although ESA model has been deeply described in previous works $[14,17,18]$, the basis of the model are given next.

It is based on the one developed by Vallet et al. [12], which assumes four basic principles: high Reynolds and Weber numbers, small difference in velocity between phases, the dispersion is calculated through a balance equation, and the mean size of liquid fragments can be obtained from the mean surface area of the liquid-gas interface per unit volume. Nevertheless, the droplet size is not analyzed in this work (because there is not experimental data to compare with), and the the description of its modeling is omitted.

The dispersion of the liquid into the gaseous ambient is modeled with a turbulent diffusion flux given by Ficks law. The transport equation of the liquid mass fraction is Equation 1, where $D_{Y, \text { eff }}$ is the diffusivity coefficient computed as in Equation 2, being $S c$ the Schmidt number. By the Kolmogorov hypothesis for small scale features of the flow, $S c=1$ can be assumed.

$$
\begin{gathered}
\frac{\partial\left(\rho Y_{f}\right)}{\partial t}+\nabla \cdot\left(\rho \boldsymbol{U} Y_{f}\right)-\nabla\left(D_{Y . e f f} \nabla Y_{f}\right)=0 \\
D_{Y, \text { eff }}=\frac{\mu_{t}}{S c}
\end{gathered}
$$

A turbulence model is necessary to estimate the turbulent viscosity, $\mu_{t}$. In this case a Reynolds-Averaged Navier-Stokes (RANS) 2-equations viscosity model is selected, concretely the SST $k$ - $\omega$. It has been proved that it is able to correctly predict the flow inside the nozzle and along the spray [14].

Once the liquid mass fraction is obtained, the density of the liquid-gas mixture is given by an equation of state such as Equation 3. Nitrogen is used for the gas phase, which is assumed to behave as an ideal and perfect gas. The liquid phase (the fuel) is n-Dodecane, as established by ECN standard. Density and bulk modulus of this phase are polynomial fittings to experimental data, as shown by Desantes et al. [17].

$$
\rho=\frac{1}{\frac{Y_{f}}{\rho_{f}}+\frac{1-Y_{f}}{\rho_{g}}}
$$

The rest of balance equations (continuity, momentum, energy and pressure) are the common ones used in compressible mono-phase solvers and can be easily found in the literature, e.g. the work of Weller et al. [19]. 
Final author version, cite as:

Payri, R., Gimeno, J., Mart-Aldarav, P. et al. "Numerical simulation of needle movement nozzle flow coupled with spray for a diesel injector using an Eulerian spray atomization model", J Braz. Soc. Mech. Sci. Eng., 39(7), pp. 2585-2592, (2017). doi:10.1007/s40430-017-0801-1

The CFD software selected to perform the calculations is OpenFOAM 2.3.0 (R), mainly because it is open source and new equations can be easily introduced to already existing codes. Thus, new solvers are easy to compile and test. Transport equations are solved within a PIMPLE (combination of Pressure Implicit with Splitting Operators -PISO- and Semi-Implicit Method for Pressure-Linked Equations -SIMPLE-) loop, which increases computational cost but ensures stability and accuracy. Upwind discretization and linear interpolation schemes are used with an Euler scheme for the time discretization. PBiCG (Preconditioned Bi-Conjugate Gradient) solver with DILU (Diagonal Incomplete LU) preconditioner is used for all variables except for the pressure, which is solved with a PCG (Preconditioned Conjugate Gradient) solver with DIC (Diagonal Incomplete Cholesky) preconditioner. A relaxation factor of 0.3 is used for the pressure, whereas a value of 0.7 is used for the rest of variables except for the density, which is solved without relaxation.

\subsection{Case set-up}

Simulations set-up is similar to the one configured in previous works [14, 17], being the main difference the needle position and movement. As mentioned above, ECN Spray A conditions [7,16] are considered. That is, a Bosch solenoid-activated injector with axial single-hole nozzle. The nominal orifice outlet diameter is $0.090 \mathrm{~mm}$, with a k-factor of $0.0015 \mathrm{~mm}$ and a fillet inlet radius of $0.025 \mathrm{~mm}$.

The reference injection conditions to compare simulations and experiments are: $150 \mathrm{MPa}$ of injection pressure, $22.8 \mathrm{~kg} / \mathrm{m}^{3}$ of ambient density, $303 \mathrm{~K}$ of ambient temperature, and the fuel is injected to the vessel at $343 \mathrm{~K}$ of temperature. For simulations with fixed needle position, it is placed at $0.1 \mathrm{~mm}$ of lift, however the initial lift of moving needle simulations is $7.5 \mu \mathrm{m}$ (it cannot be 0 due to meshing issues).

The mesh built for this study is shown in Figure 1. It is the one used for fixed needle simulatoins. Due to circumferential symmetry of the nozzle (although this is not entirely true [7]), a wedge two-dimensional domain is preferred to save computational cost. In order to ensure mesh independent results, the minimum cell count is 67402 elements, with 18 cells along the orifice outlet.

The inlet of the nozzle is the inlet boundary condition, taken as timevarying pressure (the time evolution comes from the experiments [7]) at constant temperature $(343 \mathrm{~K})$, as defined by ECN. The turbulent intensity at the inlet is $5 \%$ of the mean velocity and the turbulent length scale equal to $10 \%$ of the orifice outlet diameter. The outlet of the domain, on the right hand side, is a non-reflective or wave transmissive boundary, with a pressure value that gives an ambient density of $22.8 \mathrm{~kg} / \mathrm{m}^{3}$. The rest of boundaries of the domain are non-slip walls at constant temperature. Standard wall functions are also used. 
Final author version, cite as:

Payri, R., Gimeno, J., Mart-Aldarav, P. et al. "Numerical simulation of needle movement nozzle flow coupled with spray for a diesel injector using an Eulerian spray atomization model", J Braz. Soc. Mech. Sci. Eng., 39(7), pp. 2585-2592, (2017). doi:10.1007/s40430-017-0801-1

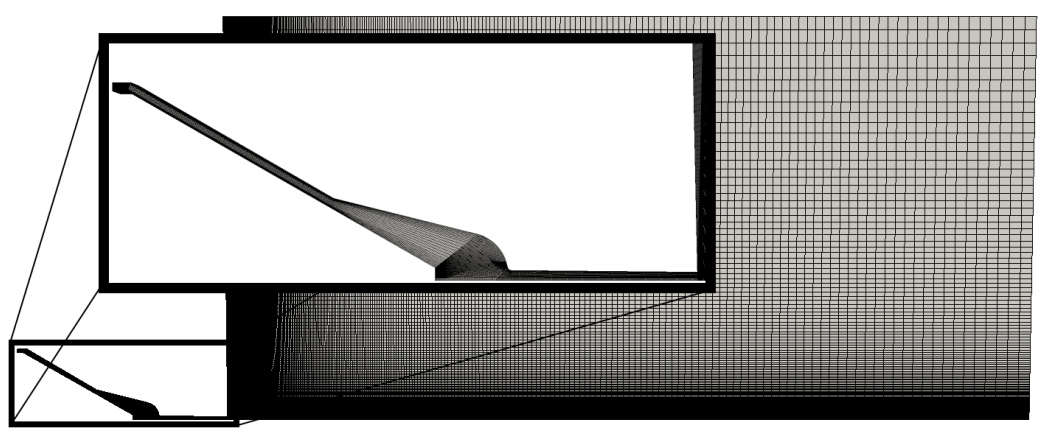

Fig. 1: Computational domain and mesh.

\subsection{Moving needle strategies}

The needle lift, measured by means of X-ray tomography [7], is shown in Figure 2a. The needle velocity has been plotted on the upper part of the figure. It is clearly seen how some of the frequencies of the signal were lost during the acquisition, proved by its peaky shape. This may lead to unstable and unrealistic internal nozzle flow pattern, so the signal has been filtered using a moving average filter. The result is represented in Figure 2b. It has been also drawn the difference between the original and filtered signal. The maximum difference is about $0.4 \mathrm{~m} / \mathrm{s}$ and is found at the peaks, as expected. By comparing these two needle velocity laws it is possible to check if this has an impact on the spray behavior.

OpenFOAM 2.3.0 @ supports mesh morphing six degree of freedom. However, for this work only the axial movement is needed. Mesh motion is based on solving the cell-center Laplacian for the given component of the motion velocity, and cells are deformed accordingly in all directions to keep cell quality (skewness, aspect ratio) under acceptable levels. Figure 3 shows how cells around the needle are modified depending on the needle position: minimum or maximum lift.

\section{Results and discussion}

\subsection{Nozzle flow}

First parameters to be analyzed are the mas flow rate and momentum flux, together with the non-dimensional coefficients that define the nature of the flow: $C_{v}, C_{a}$ and $C_{d}$, following Desantes et al. [20] procedure. Steady state values of coefficients, including experimental ones, are presented in Table 1. All simulations predict almost the same value for the discharge coefficient $C_{d}$, $2 \%$ lower than the experimental. This is due to the under-prediction of the velocity coefficient, which means that simulations give a velocity slightly lower 
Final author version, cite as:

Payri, R., Gimeno, J., Mart-Aldarav, P. et al. "Numerical simulation of needle movement nozzle flow coupled with spray for a diesel injector using an Eulerian spray atomization model", J Braz. Soc. Mech. Sci. Eng., 39(7), pp. 2585-2592, (2017). doi:10.1007/s40430-017-0801-1
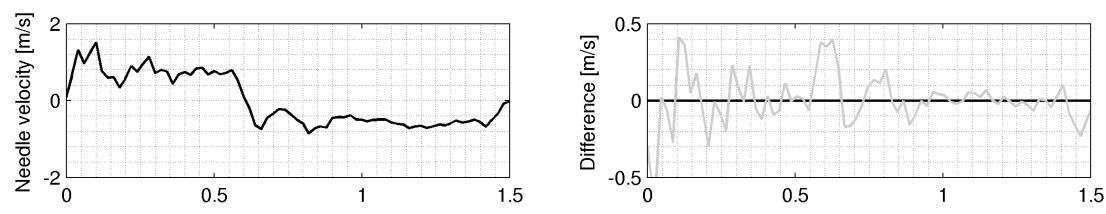

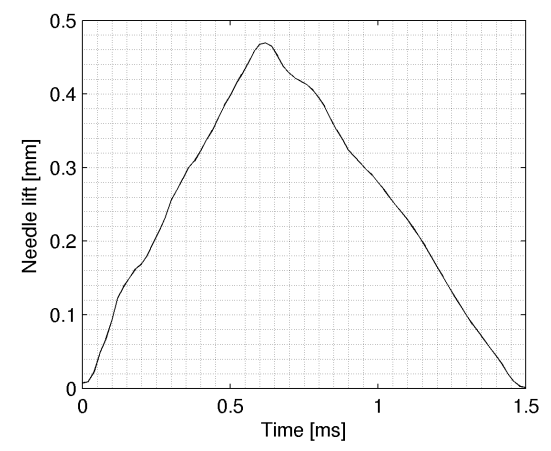

(a) Needle lift.

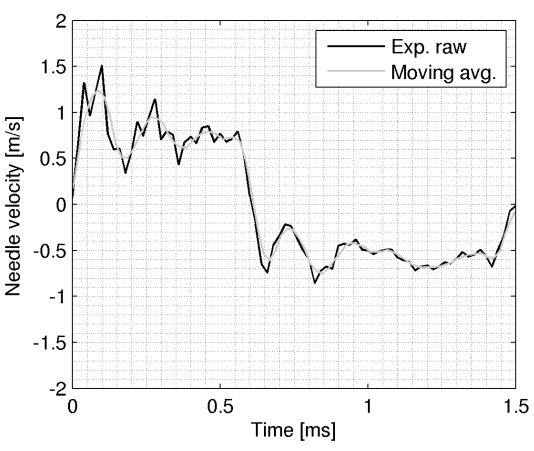

(b) Needle velocity filtered.

Fig. 2: Experimental needle lift and velocity at Spray A conditions.

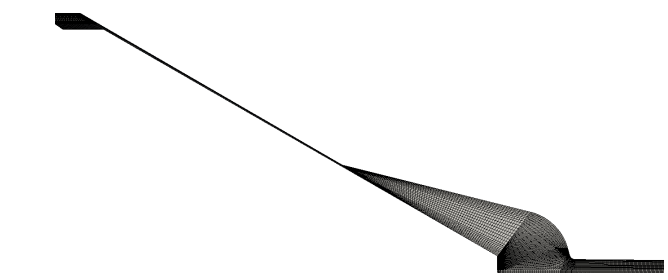

(a) $t=0 \mathrm{~ms}$.

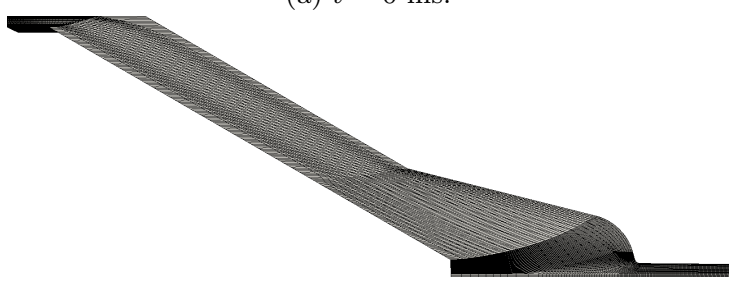

(b) $t=0.6 \mathrm{~ms}$.

Fig. 3: Mesh deformation due to needle movement.

than experiments. This difference may be related to uncertainties on reference density value. Nevertheless, differences are small.

Comparing different simulations, both curves used to model the needle velocity lead to the same values on coefficients, quite similar to the calculation without mesh movement. So, if the objective is to obtain steady state values, the needle lift profiles seems to be not needed. 
Final author version, cite as:

Payri, R., Gimeno, J., Mart-Aldarav, P. et al. "Numerical simulation of needle movement nozzle flow coupled with spray for a diesel injector using an Eulerian spray atomization model", J Braz. Soc. Mech. Sci. Eng., 39(7), pp. 2585-2592, (2017). doi:10.1007/s40430-017-0801-1

Table 1: Non-dimensional coefficients that define the hydraulic performance of the nozzle.

\begin{tabular}{cccc}
\hline & $\boldsymbol{C}_{\boldsymbol{v}}$ & $\boldsymbol{C}_{\boldsymbol{a}}$ & $\boldsymbol{C}_{\boldsymbol{d}}$ \\
\hline Experimental & $0.94 \pm 0.01$ & $0.98 \pm 0.01$ & $0.92 \pm 0.01$ \\
Fixed mesh & 0.92 & 0.98 & 0.90 \\
Moving mesh & 0.90 & 0.99 & 0.90 \\
Filtered signal & 0.90 & 0.99 & 0.90 \\
\hline
\end{tabular}

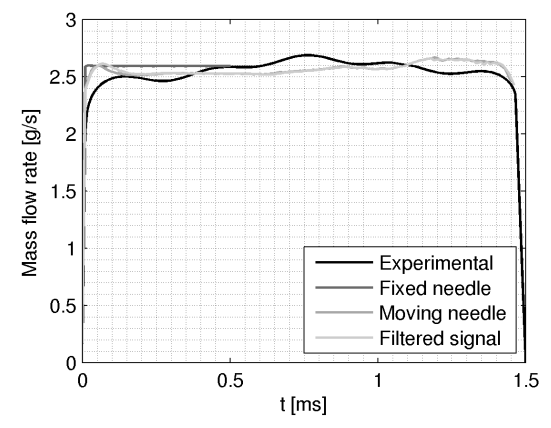

(a) Mass flow rate.

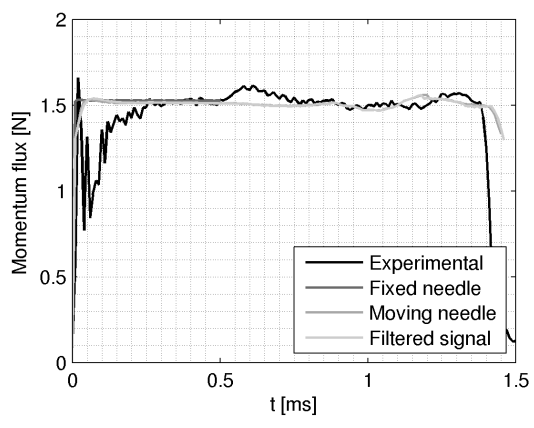

(b) Momentum flux.

Fig. 4: Mass flow rate and momentum flux time evolutions of simulations and experiments.

Mass flow rate and momentum flux signals are depicted in Figure 4. Simulation with fixed mesh only reaches $0.5 \mathrm{~ms}$, which is enough time to get to the steady state. Both needle velocity signals generate almost the same mass flow rate and momentum flux; once again, the filtering on the experimental data for the needle lift seems to have negligible effects. Time varying pressure inlet boundary by itself is not enough to obtain the oscillations in mass flow and momentum experimentally observed. In fact, when that condition is combined with needle movement, oscillations grow but do not follow experimental data. This means that pressure signal on the rail should not be used as boundary condition in internal nozzle flow simulations.

Differences between simulations and experiments are specially large at start of injection. This is related to the initial conditions. In this case, the nozzle is initially filled with stagnated liquid at injection pressure. As it has been proved, that initialization leads to higher mass flow rate values in the early stages of the injection. This issue can be solved by initializing the orifice filled with gas at ambient conditions and the rest of the nozzle filled with liquid at injection conditions [21].

Another significant difference between simulation strategies is found at temperature contours, shown in Figure 5. In the case of fixed needle, there is a temperature drop on the core of the flow of about $20 \mathrm{~K}$ from $343 \mathrm{~K}$, which is the fuel temperature set at boundaries. A small increase of temperature is 
Final author version, cite as:

Payri, R., Gimeno, J., Mart-Aldarav, P. et al. "Numerical simulation of needle movement nozzle flow coupled with spray for a diesel injector using an Eulerian spray atomization model", J Braz. Soc. Mech. Sci. Eng., 39(7), pp. 2585-2592, (2017). doi:10.1007/s40430-017-0801-1

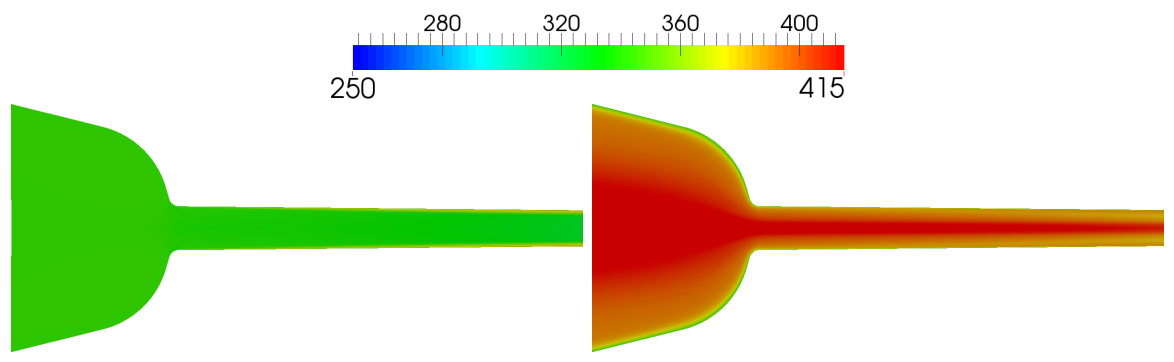

(a) Fixed needle.

(b) Moving needle.

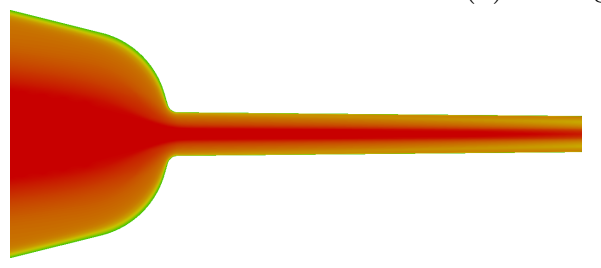

(c) Filtered signal.

Fig. 5: Temperature in $\mathrm{K}$ contours of all simulations at $0.5 \mathrm{~ms}$ after start of injection.

observed next to walls. However, in both simulations with needle movement, the temperature inside the sac and orifice goes up to almost $400 \mathrm{~K}$ (not in the walls where temperature is set by boundary conditions). That increase in temperature is due to the viscous heating of the flow trespassing the needle seat when the lift is small (see Figure 3a), and for longer times after start of injection diminishes, reaching temperature levels similar to the ones observed in the simulation with fixed needle position. Different fuel temperatures at the orifice exit would lead to different droplet size and evaporation rates during the injection event $[3,22]$.

\subsection{Near field spray development}

To continue the analysis once the internal flow differences have been commented, spray parameters need to be analyzed. Spray penetration, defined by ECN as the maximum axial distanced where the liquid mass fraction is above $0.1 \%$ [16] is plotted in Figure 6. Experimental spray penetration was measured by Argonne National Laboratories, who used X-ray tomography to measure the spray structure in the near-field [23]. Simulation with fixed needle slightly over-estimates the near-field spray penetration, whilst simulations with moving needle give quite similar curves than experiments. Both simulation curves overlaps, one more evidence that filtering the needle velocity may not be needed.

This difference in spray penetration is explained by the different orifice exit velocity that is obtained by the simulations. The axial velocity on spray 
Final author version, cite as:

Payri, R., Gimeno, J., Mart-Aldarav, P. et al. "Numerical simulation of needle movement nozzle flow coupled with spray for a diesel injector using an Eulerian spray atomization model", J Braz. Soc. Mech. Sci. Eng., 39(7), pp. 2585-2592, (2017). doi:10.1007/s40430-017-0801-1

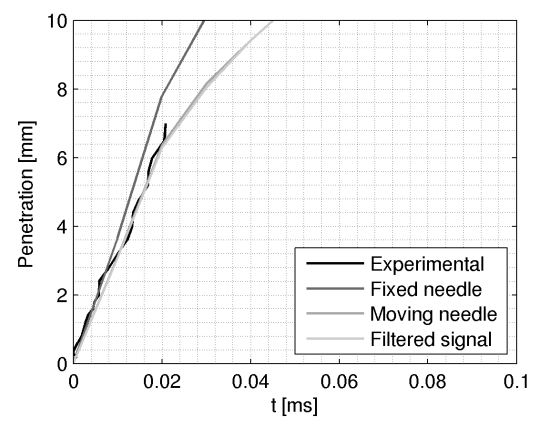

Fig. 6: Spray penetration.

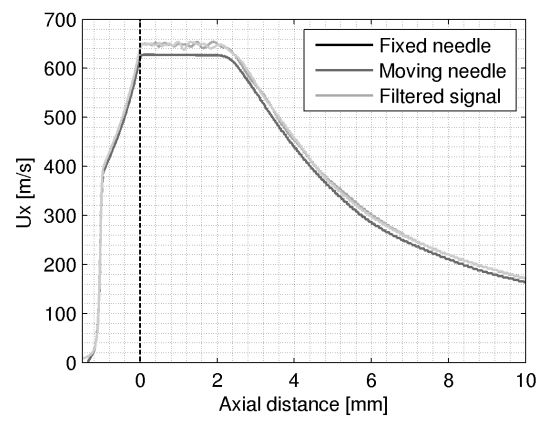

Fig. 7: Axial velocity distribution along the spray axis at $0.5 \mathrm{~ms}$.

axis is at $0.5 \mathrm{~ms}$ plotted in Figure 7 , where the vertical dotted line marks the orifice outlet. Inside the sac and orifice velocities are similar, but in the case of moving needle simulation, it reaches a higher value at orifice exit. This is due to a lower density inside the orifice given by a higher temperature (see Figure 5).

Following, spray structure obtained by simulations is compared with experiments in Figure 8 in terms of projected density [23], which is a line of sight magnitude related to the liquid concentration. The first $10 \mathrm{~mm}$ of the spray are represented. Barely no differences are observed between different simulations. Nevertheless, when comparing with experiments, it is clear that the model over-predicts spray density beyond $5 \mathrm{~mm}$. That is a common issue of computational models [24]. Regardless that, the dense region of the spray (red area) is very well predicted by the model in both width and length.

\section{Conclusions}

Spray A conditions have been simulated by using the ESA model. Needle movement has been taken into account under different approaches: fixed nee- 
Final author version, cite as:

Payri, R., Gimeno, J., Mart-Aldarav, P. et al. "Numerical simulation of needle movement nozzle flow coupled with spray for a diesel injector using an Eulerian spray atomization model", J Braz. Soc. Mech. Sci. Eng., 39(7), pp. 2585-2592, (2017). doi:10.1007/s40430-017-0801-1

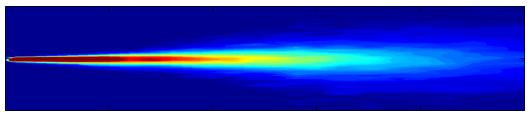

(a) Experimental.

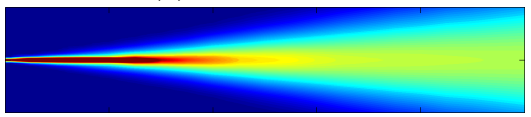

(c) Moving needle.

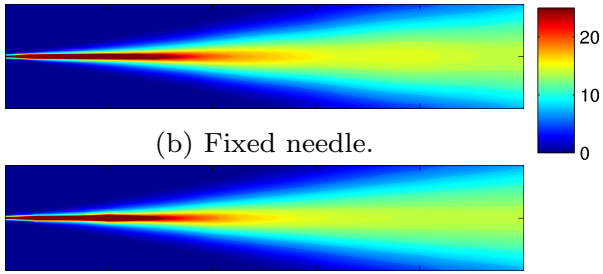

(d) Filtered signal.

Fig. 8: Projected density contours in $\mu \mathrm{g} / \mathrm{mm}^{2}$ at $0.5 \mathrm{~ms}$ after start of injection.

dle, the raw experimental data for needle lift, and filtered signal to remove possible instabilities. The following conclusions can be drawn from the current work:

- No clear difference has been observed between raw lift data and the filtered signal. There is no need of post-processing the needle lift data. Although the acquisition frequency seemed to be low, is enough for performing simulations.

- Needle movement is needed to capture oscillations experimentally observed in mass flow rate and momentum flux. However, it must be combined with the right inlet boundary condition and the proper initialization.

- Errors in spray penetration are minimized if needle movement is considered.

- Very low needle lift leads to a significant heating of the fuel inside the nozzle due to viscous dissipation. This effect diminishes for long injections, but for timings similar to real engine operation this effect has to be considered.

- Spray structure is generally well predicted, except that ESA computational model over-predicts fuel concentration for distances longer than $5 \mathrm{~mm}$.

Therefore, when the needle lift is available, it is recommended to consider it in the simulations to improve predictions in both nozzle and spray parameters. Special attention must be paid to inlet boundary condition and initialization of simulations. Nonetheless, there is still work to do to improve Diesel spray models.

Acknowledgements This research was performed in the frame of the project "Estudio de la interacción chorro-pared en condiciones realistas de motor (SPRAY WALL)" reference TRA2015-67679-c2-1-R from Ministerio de Economía y Competitividad (Spanish Ministry of Economy).

\section{References}

1. Fajgenbaum R, dos Santos RG (2016) Influence of fuel temperature on atomization parameters in a pressure-swirl atomizer from a port fuel injector by Shadowgraphy technique. Journal of the Brazilian Society of Mechanical Science and Engineering 38:1877-1892. doi:10.1007/s40430-015-0443-0 
Final author version, cite as:

Payri, R., Gimeno, J., Mart-Aldarav, P. et al. "Numerical simulation of needle movement nozzle flow coupled with spray for a diesel injector using an Eulerian spray atomization model", J Braz. Soc. Mech. Sci. Eng., 39(7), pp. 2585-2592, (2017). doi:10.1007/s40430-017-0801-1

2. He Z, Guo G, Tao X, Zhong W, Leng X, Wang Q (2016) Study of the effect of nozzle hole shape on internal flow and spray characteristics. International Communications in Heat and Mass Transfer 71:1-8. doi:10.1016/j.icheatmasstransfer.2015.12.002

3. Loaiza JCV, Sánchez FZ, Braga SL (2016) Combustion study of reactivity-controlled compression ignition (RCCI) for the mixture of diesel fuel and ethanol in a rapid compression machine. Journal of the Brazilian Society of Mechanical Science and Engineering 38:1073-1085. doi:10.1007/s40430-015-0400-y

4. Salvador FJ, Romero JV, Roselló MD, Jaramillo D (2015) Numerical simulation of primary atomization in diesel spray at low injection pressure. Journal of Computational and Applied Mathematics 291:94-102. doi:10.1016/j.cam.2015.03.044

5. Strotos G, Koukpuvinis P and Theodorakakos A (2015) Transient heating effects in high pressure Diesel injector nozzles. International Journal of Heat and Fluid Flow 51:257-267. doi:10.1016/j.ijheatfluidflow.2014.10.010

6. Macian V, Bermúdez V, Payri R, Gimeno J (2003) New technique for determination of internal geometry of a Diesel nozzle with the use of silicone methodology. Experimental Techniques, 39:39-43. doi:10.1111/j.1747-1567.2003.tb00107.x

7. Kastengren AL, Tiloco FZ, Powell CF, Manin J, Pickett LM, Payri R, Bazyn T (2012) Engine Combustion Network (ECN): Measurements of Nozzle Geometry and Hydraulic Behavior. Atomization and Sprays 22:1011-1052. doi:10.1615/AtomizSpr.2013006309

8. Kastengren AL, Tiloco FZ, Duke DJ, Powell CF, Zhang X, Moon S (2014) Time-resolved X-Ray Radiography of Sprays from Engine Combustion Network Spray A Diesel Injectors. Atomization and Sprays 24:251-272. doi:10.1615/AtomizSpr.2013008642

9. Lee WG, Reitz RD (2009) A Numerical Investigation of Transient Flow and Cavitation within Minisac and VCO Diesel Injector Nozzles. Proceedings of the 2009 Spring Technical Conference of the ASME Internal Combustion Engine Division 643-653. doi:10.1115/ICES2009-76148

10. Payri R, Gimeno J, Viera JP, Plazas AH (2013) Needle lift profile influence on the vapor phase penetration for a prototype diesel direct acting piezoelectric injector. Fuel 113:257-265. doi:10.1016/j.fuel.2013.05.057

11. Bermúdez V, Payri R, Salvador FJ, Plazas AH (2005) Study of the influence of nozzle seat type on injection rate and spray behavior. IMechE. Part D: Journal of Automobile Engineering 219:677-689. doi:10.1243/095440705X28303

12. Vallet A, Burluka AA, Borghi R (2001) Development of a Eulerian Model for the "Atomization" of a Liquid Jet. Atomization and Sprays 11:619-642. doi:10.1615/AtomizSpr.v11.i6.20

13. García-Oliver JM, Pastor JM, Pandal A, Trask N, Baldwing E, Shcmidt DP (2013) Diesel Spray CFD Simulations Based on the $\Sigma-Y$ Eulerian Atomization Model. Atomization and Sprays 23:71-95. doi:10.1615/AtomizSpr.2013007198

14. Salvador FJ, Gimeno J, Pastor JM, Martí-Aldaraví P (2015) Effect of turbulence model and inlet boundary condition on the Diesel spray behavior by an Eulerian Spray Atomization (ESA) model. International Journal of Multiphase Flow, 65:108-116. doi:10.1016/j.ijmultiphaseflow.2014.06.003

15. Anvari S, Taghavifa H, Khalilarya S, Jafarmadar S (2016) Numerical simulation of diesel injector nozzle flow and in-cylinder spray evolution. Applied Mathematical Modelling 40:8617-8629. doi:10.1016/j.apm.2016.05.017

16. Bardi M, Payri R, Malbec LM, Bruneaux G, Pickett LM, Manin J, Bazyn T, Genzale C (2012) Engine Combustion Network: Comparison of Spray Development, Vaporization, and Combustion in Different Combustion Vessels. Atomization and Sprays 22:807-842. doi:10.1615/AtomizSpr.2013005837

17. Desantes JM, Payri R, Gimeno J, Martí-Aldaraví P (2014) Simulation of the First Millimeters of the Diesel Spray by an Eulerian Spray Atomization Model Applied on ECN Spray A Injector. SAE Technical Paper 2014-01-1418. doi:10.4271/2014-01-1418

18. Payri R, Ruiz S, Gimeno J, Martí-Aldaraví P (2015) Verification of a new CFD compressible segregated and multi-phase solver with different flux update-equations sequences. Applied Mathematical Modelling, 39:851-861. doi:10.1016/j.apm.2014.07.011

19. Weller HG, Tabor G, Jasak H, Fureby C (1998) A tensorial approach to computational continuum mechanics using object-oriented techniques. Computer and Physics 12:620-631. doi: $10.1063 / 1.168744$ 
Final author version, cite as:

Payri, R., Gimeno, J., Mart-Aldarav, P. et al. "Numerical simulation of needle movement nozzle flow coupled with spray for a diesel injector using an Eulerian spray atomization model", J Braz. Soc. Mech. Sci. Eng., 39(7), pp. 2585-2592, (2017). doi:10.1007/s40430-017-0801-1

20. Desantes JM, Payri R, Pastor JM, Gimeno J (2005) Experimental characterization of internal nozzle flow and diesel spray behavior. Part 1: Non-evaporative conditions, Atomization and Sprays 17:315-345. doi:10.1615/AtomizSpr.v15.i5.20

21. Payri R, Gimeno J, Martí-Aldaraví P, Carreres M (2015) Assessment on Internal Nozzle Flow Initialization in Diesel Spray Simulations. SAE Technical Paper 2015-01-0921. doi:10.4271/2015-01-0921

22. Rybdylova O, Al Qubeissi M, Braun M, Crua C, Manin J, Pickett LM, de Sercey G, Sazhina EM, Sazhin SS, Heikal M (2016) A model for droplet heating and its implementation into ANSYS Fluent, International Communications in Heat and Mass Transfer, 76:265-270. doi:10.1016/j.icheatmasstransfer.2016.05.032

23. Kastengren AL, Powell CF, Wang Y, Im KS, Wang J (2009) X-Ray Radiography Measurements of Diesel Spray Structure at Engine-Like Ambient Density. Atomization and Sprays 19:1031-1044. doi:10.1615/AtomizSpr.v19.i11.30

24. Xue Q, Battistoni M, Som S, Quan S, Senecal PK, Pomraning E, Schmidt DP (2014) Eulerian CFD Modelling of Coupled Nozzle Flow and Spray with Validation Against X-Ray Radiography Data. SAE International Journal of Engines, 7:1061-1072. doi:10.4271/201401-1425 